\title{
Extensive CFTR Gene Analysis Revealed a Higher Occurrence of Cystic Fibrosis Transmembrane Regulator-Related Disorders (CFTR-RD) among CF Carriers
}

\author{
Maria Valeria Esposito ${ }^{1}$, Achille Aveta ${ }^{2}$, Marika Comegna ${ }^{1,3}$, Gustavo Cernera ${ }^{1,3}$, \\ Paola Iacotucci ${ }^{4}$, Vincenzo Carnovale ${ }^{4}$, Giovanni Taccetti ${ }^{5}$, Vito Terlizzi ${ }^{5, *}$ and \\ Giuseppe Castaldo ${ }^{1,3}$ \\ 1 CEINGE-Biotecnologie Avanzate, 80131 Naples, Italy; espositomaria@ceinge.unina.it (M.V.E.); \\ marika.comegna@unina.it (M.C.); gustavo.cernera@unina.it (G.C.); giuseppe.castaldo@unina.it (G.C.) \\ 2 Dipartimento di Neuroscienze, Sezione di Urologia, Università di Napoli Federico II, 80131 Naples, Italy; \\ achille-aveta@hotmail.com \\ 3 Dipartimento di Medicina Molecolare e Biotecnologie Mediche, Università di Napoli Federico II, \\ 80131 Naples, Italy \\ 4 Dipartimento di Scienze Mediche Traslazionali, Università di Napoli Federico II, 80131 Naples, Italy; \\ paola.iacotucci@unina.it (P.I.); vincenzo.carnovale@unina.it (V.C.) \\ 5 Dipartimento di Pediatria, Centro Regionale Toscano per la Fibrosi Cistica, \\ Azienda Ospedaliero-Universitaria Meyer, 50139 Florence, Italy; giovanni.taccetti@meyer.it \\ * Correspondence: vito.terlizzi@meyer.it; Tel.: +39-05-5566-2474
}

Received: 28 September 2020; Accepted: 25 November 2020; Published: 27 November 2020

check for updates

\begin{abstract}
Background: A wide range of cystic fibrosis (CF)-related conditions are reported in $\mathrm{CF}$ carriers, but no study has explored the possibility that such subjects may be affected by cystic fibrosis transmembrane regulator-related disorders (CFTR-RD). No data are available so far on the occurrence of CFTR-RD among CF carriers. Methods: We studied 706 CF carriers-first- and second-degree relatives of CF patients that carried the parental mutation; such subjects were divided in two groups: a first group (353 subjects, group A) performed at first only the analysis of the CFTR proband mutation; we retrospectively evaluated the number of cases that had been diagnosed as CFTR-RD based on subsequent symptoms; a second group (353 subjects, group B) performed extensive CFTR molecular analysis in absence of any reported symptoms, followed by a clinical evaluation in cases that carry a second CFTR mutation; we evaluated the number of cases that prospectively were diagnosed as CFTR-RD. Results: We found seven (2.0\%) out of 353 subjects of group A and $24(6.8 \%)$ out of 353 subjects of group B as affected by CFTR-RD (chi square, $p=0.002$ ). Conclusions: A percentage of CF carriers are affected by undiagnosed CFTR-RD. Genetic tasting scanning analysis helps to identify CFTR-RD, some of which may benefit from follow-up and specific therapies improving their outcome.
\end{abstract}

Keywords: consanguineous; CBAVD; sweat chloride

\section{Introduction}

Various studies reported a higher risk for cystic fibrosis (CF)-related conditions including infertility, pancreatitis, sinusitis, and respiratory infections among CF carriers [1-3]. A recent study that included about 20,000 CF carriers and a large control population concluded that 57 CF-related clinical conditions are significantly more frequent among CF carriers [4]. However, these studies did not consider the possibility that a percentage of CF carriers would carry a second mutation and would be affected by cystic fibrosis transmembrane regulator-related disorders (CFTR-RD) [5]. No data are available 
on the occurrence of CFTR-RD among CF carriers, because they are usually revealed as being the consanguineous of a patient with $\mathrm{CF}$, and they are tested only for the mutations previously found in the family proband [6]. As there is no medical evaluation or an extensive study of the CFTR gene, the identification of subjects with CFTR-RD is probably underestimated. Although patients with CFTR-RD have a less severe clinical expression compared to patients with $\mathrm{CF}$, they may develop late complications [7]. The rapid diagnosis and access to specialized follow-up and care is the most relevant point in the outcome of these patients [8].

In recent years, we sporadically observed that first and second degree relatives of CF patients may develop CFTR-RD [9], and the extensive molecular analysis in these subjects revealed a second CFTR mutation, usually mild [10], in addition to the known family mutation.

For these reasons, the aim of our study was to evaluate the occurrence of CFTR-RD among CF carriers.

\section{Methods}

We studied all subjects that had resulted heterozygous carriers of the proband mutation being first- and second-degree relatives of patients with CF diagnosed at CF centers of Naples and Florence, Italy. All the subjects included in the study released the informed consent to perform the extensive CFTR molecular analysis and to use their data anonymously.

Sweat test (ST) was analyzed according to guidelines [11]. We considered pathological a value $>60 \mathrm{mmol} / \mathrm{L}$ and intermediate a value ranging 40 to $59 \mathrm{mmol} / \mathrm{L}$. The pancreatic status was evaluated testing fecal pancreatic elastase-1 (using a cut-off of $200 \mathrm{mcg} / \mathrm{g}$ ) measured in the absence of acute pancreatitis or gastrointestinal diseases; pancreatitis was defined as acute, recurrent, or chronic, according to the report from the international study group of pediatric pancreatitis [12] excluding all known causes of pancreatitis. The evaluation of sinonasal pathology was performed by clinical evaluation followed by rhinoscopy and in cases of symptoms by CT scanning, as previously described [13,14].

\section{Results}

We identified 706 subjects and divided them into two groups: (i) a first group of 353 subjects (188 females, mean age: 38 years, range: 19-46) performed at first only the analysis of the CFTR proband mutation; we retrospectively evaluated the number of cases that had been diagnosed as CFTR-RD for subsequent symptoms (group A); (ii) a second group of 353 apparently asymptomatic subjects (194 females, mean age: 38 years; range: $20-46$ ) in which we performed the extensive CFTR molecular analysis [15] including the analysis of the most frequent rearrangements [16] and sweat chloride testing (group B). The subjects in which the analysis revealed a second mutation were evaluated by a physician trained in the field of CF to verify how many of them were affected by CFTR-RD.

As shown in Table 1, within group A, seven (2.0\%) out of 353 subjects had been diagnosed as CFTR-RD, while within group B, $24(6.8 \%)$ out of 353 subjects were finally diagnosed as CFTR-RD (chi square, $p=0.002$ ). In detail, within group $A$, all seven subjects diagnosed as CFTR-RD had an intermediate ST (i.e., between 41 and $53 \mathrm{mmol} / \mathrm{L}$ ), two CFTR mutations, recurrent or chronic pancreatitis (four cases), bronchiectasis at TC scan (two cases), or congenital bilateral absence of the vas deferens ( 1 case). Within group B, 32 subjects were revealed as compound heterozygous for two CFTR mutations; of these, eight had a normal ST and were free of CF-related symptoms, while among the 24 subjects revealed as CFTR-RD, all had an intermediate ST (between 36 and $56 \mathrm{mmol} / \mathrm{L}$ ) and mono-organ involvement, i.e., bronchiectasis, four cases; congenital bilateral absence of vas deferens (CBAVD), three cases; recurrent pancreatitis, three cases; chronic pancreatitis, six cases; hypochloremic metabolic alkalosis, four cases; nasal polyposis requiring surgery, four cases. Eight other cases were revealed as double heterozygous for two CFTR mutations (from 25 to 32 in Table 1); they had a normal ST and resulted free from symptoms. These subjects are currently in clinical follow-up. 
Table 1. Subjects diagnosed as cystic fibrosis transmembrane regulator-related disorders (CFTR-RD) by symptoms (A) or following molecular analysis in the absence of reported symptoms (B). CBAVD, congenital bilateral absence of vas deferens; $\mathrm{CP}$, chronic pancreatitis; NP, nasal polyposis; $\mathrm{RP}$, recurrent pancreatitis.

\begin{tabular}{|c|c|c|c|}
\hline Case & CFTR Genotype & Sweat Chloride $(\mathrm{mmol} / \mathrm{L})$ & Clinical Expression \\
\hline \multicolumn{4}{|c|}{ Group A } \\
\hline 1 & W1282X/D1152H & 51 & Bronchiectasis \\
\hline 2 & F508del/D1152H & 43 & $\mathrm{CP}$ \\
\hline 3 & G542X/G85E & 43 & $\mathrm{CP}$ \\
\hline 4 & F508del/[G576; R668C] & 41 & $\mathrm{RP}$ \\
\hline 5 & F508del/[5T;12Tg] & 50 & $\mathrm{RP}$ \\
\hline 6 & R1066C/[5T;12Tg] & 48 & CBAVD \\
\hline 7 & F508del/D192G & 53 & Bronchiectasis \\
\hline \multicolumn{4}{|c|}{ Group B } \\
\hline 1 & F508del/[R74W; D1270N] & 41 & Bronchiectasis \\
\hline 2 & F508del/621+3A>G & 40 & Bronchiectasis \\
\hline 3 & R1158X/[5T;12Tg] & 40 & Bronchiectasis \\
\hline 4 & Q220X/D1152H & 38 & Bronchiectasis \\
\hline 5 & 1717-1G>A/D1152H & 48 & CBAVD \\
\hline 6 & F508del/D1152H & 46 & CBAVD \\
\hline 7 & F508del/[R74W; D1270N] & 41 & CBAVD \\
\hline 8 & F508del/[5T;12Tg] & 36 & $\mathrm{CP}$ \\
\hline 9 & F508del/[5T;12Tg] & 36 & $\mathrm{CP}$ \\
\hline 10 & 1717-1G>A/[G576A-R668C] & 40 & $\mathrm{CP}$ \\
\hline 11 & F508del/[5T;12Tg] & 48 & $\mathrm{CP}$ \\
\hline 12 & S1455X/D1152H & 47 & $\mathrm{CP}$ \\
\hline 13 & V201M/D1152H & 40 & $\mathrm{CP}$ \\
\hline 14 & F508del; D1168G & 40 & Metabolic alkalosis \\
\hline 15 & D1152H/[R74W; D1270N] & 51 & Metabolic alkalosis \\
\hline 16 & E585X/[5T;12Tg] & 47 & Metabolic alkalosis \\
\hline 17 & I506V/[5T;12Tg] & 46 & Metabolic alkalosis \\
\hline 18 & 2183AA $>$ G/L684S & 51 & $\mathrm{NP}$ \\
\hline 19 & $\mathrm{~L} 967 \mathrm{~F} / 3849+10 \mathrm{KbC}>\mathrm{T}$ & 42 & NP \\
\hline 20 & 2183AA>G/D1152H & 48 & $\mathrm{NP}$ \\
\hline 21 & F508del/D1152H & 56 & $\mathrm{NP}$ \\
\hline 22 & F508del/[5T;12Tg] & 42 & $\mathrm{RP}$ \\
\hline 23 & G542X/L997F & 48 & $\mathrm{RP}$ \\
\hline 24 & G542X/[5T;12Tg] & 49 & $\mathrm{RP}$ \\
\hline 25 & F508del/[5T;12Tg] & 22 & Health \\
\hline 26 & G542X/D1152H & 29 & Health \\
\hline 27 & G542X/R74W & 24 & Health \\
\hline 28 & N1303K/[5T;12Tg] & 30 & Health \\
\hline 29 & F508del/[5T;12Tg] & 28 & Health \\
\hline 30 & F508del/[R74W; D1270N] & 30 & Health \\
\hline 31 & F508del/[5T;11Tg] & 30 & Health \\
\hline 32 & F508del/[5T;11Tg] & 23 & Health \\
\hline
\end{tabular}




\section{Discussion}

These data indicate that CF carriers have a higher risk to be affected by CFTR-RD, but most likely this condition is underestimated. Performing an extensive molecular analysis of CFTR mutations and ST, there is a significantly higher number of CFTR-RD cases identified in apparently asymptomatic subjects compared to the number of cases diagnosed only by symptoms. In fact, ST resulted in intermediate range in all cases diagnosed as CFTR-RD, while it was normal in all asymptomatic subjects, independent of CFTR genotype. Most cases diagnosed as CFTR-RD have a severe mutation (usually present in the consanguineous affected by $\mathrm{CF}$ ) and a residual function mutation, among which the most frequent are the [5T;12Tg] complex allele [10], the D1152H [17], or several complex alleles that are associated with some residual activity of the CFTR protein [18] or non CF-causing mutations that, however, can cause CFTR-RD, such as L997F associated with recurrent pancreatitis [19,20]. However, such mutations were present (in trans with a severe mutation) also in a few subjects that did not develop CFTR-RD (at least so far), indicating that the final diagnosis of CFTR-RD must be based on clinical, ST, and molecular data.

Finally, some of these residual function mutations, such as D1152H, can cause CF over time [17,21,22], generally associated with a lung disease that is delayed in onset and slower in progression than more common forms of $\mathrm{CF}$; however, they can determine a markedly reduced life expectancy [23,24]. The FDA approved the use of ivacaftor, a CFTR potentiator, to treat patients with selected residual function mutations, such as $\mathrm{D} 1152 \mathrm{H}$, and recently, a clinically significant improvement was evident at 1 month and maintained at 12 months [25].

\section{Conclusions}

We strongly suggest that the first and second degree relatives of CF patients should be routinely tested by sweat testing and genetic analysis whose cost is now reduced [16], in order to define their genetic and thus clinical status that may result in the early diagnosis of CFTR-RD.

Author Contributions: Conceptualization, G.C. (Giuseppe Castaldo); methodology, G.C. (Giuseppe Castaldo); data curation: A.A. (patients with CBAVD), P.I., V.C., G.T. and V.T. (other patients); CFTR genetic analysis: M.V.E., M.C. and G.C. (Gustavo Cernera); writing-review and editing: G.C. (Gustavo Cernera) and V.T. All authors have read and agreed to the published version of the manuscript.

Funding: This research received no external funding.

Acknowledgments: We gratefully acknowledge the contribution of Regione Campania, quota vincolata per la prevenzione e cura della Fibrosi Cistica L. 548/94-Ricerca, FSN 2015-2018.

Conflicts of Interest: The authors declare no conflict of interest.

\section{References}

1. Casals, T.; De-Gracia, J.; Gallego, M.; Dorca, J.; Rodríguez-Sanchón, B.; Ramos, M.D.; Gimenez, J.; Cisteró-Bahima, A.; Olveira, C.; Estivill, X. Bronchiectasis in adult patients: An expression of heterozygosity for CFTR gene mutations? Clin. Genet. 2004, 65, 490-495. [CrossRef]

2. Cohn, J.A.; Neoptolemos, J.P.; Feng, J.; Yan, J.; Jiang, Z.; Greenhalf, W.; Mcfaul, C.; Mountford, R.; Sommer, S.S. Increased risk of idiopathic chronic pancreatitis in cystic fibrosis carriers. Hum. Mutat. 2005, 26, 303-307. [CrossRef]

3. Wang, X.; Kim, J.; McWilliams, R.; Cutting, G.R. Increased prevalence of chronic rhinosinusitis in carriers of a cystic fibrosis mutation. Arch. Otolaryngol. Head Neck Surg. 2005, 131, 237-240. [CrossRef]

4. Miller, A.C.; Comellas, A.P.; Hornick, D.B.; Stoltz, D.A.; Cavanaugh, J.E.; Gerke, A.K.; Welsh, M.J.; Zabner, J.; Polgreen, L.A. Cystic fibrosis carriers are at increased risk for a wide range of cystic fibrosis-related conditions. Proc. Natl. Acad. Sci. USA 2020, 117, 1621-1627. [CrossRef]

5. Bombieri, C.; Claustres, M.; De Boeck, K.; Derichs, N.; Dodge, J.; Girodon, E.; Sermet, I.; Schwarz, M.; Tzetis, M.; Wilschanski, M.; et al. Recommendations for the classification of diseases as CFTR-related disorders. J. Cyst. Fibros. 2011, 10, S86-S102. [CrossRef] 
6. Dequeker, E.; Cuppens, H.; Dodge, J.; Estivill, X.; Goossens, M.; Pignatti, P.F.; Scheffer, H.; Schwartz, M.; Schwarz, M.; Tümmler, B.; et al. Recommendations for quality improvement in genetic testing for cystic fibrosis. European Concerted Action on Cystic Fibrosis. Eur. J. Hum. Genet. 2000, 8 (Suppl. 2), S2-S12. [CrossRef]

7. Kilinc, A.A.; Alishbayli, G.; Taner, H.E.; Cokugras, F.C.; Cokugras, H. Clinical characteristics and genetic analysis of cystic fibrosis transmembrane conductance reseptor-related disease. Pediatr. Int. 2020, 62, 629-633. [CrossRef]

8. Michl, R.K.; Tabori, H.; Hentschel, J.; Beck, J.F.; Mainz, J.G. Clinical approach to the diagnosis and treatment of cystic fibrosis and cftr-related disorders. Expert Rev. Respir. Med. 2016, 10, 1177-1186. [CrossRef]

9. Comegna, M.; Maruotti, G.M.; Sarno, L.; Cernera, G.; Gelzo, M.; Guida, M.; Zullo, F.; Zarrilli, F.; Castaldo, G. Prenatal diagnosis of cystic fibrosis and hemophilia: Incidental findings and weak points. Diagnostics 2019, 10, 7. [CrossRef]

10. Amato, F.; Bellia, C.; Cardillo, G.; Castaldo, G.; Ciaccio, M.; Elce, A.; Lembo, F.; Tomaiuolo, R. Extensive molecular analysis of patients bearing CFTR-related disorders. J. Mol. Diagn. 2012, 14, 81-89. [CrossRef]

11. LeGrys, V.A.; Yankaskas, J.R.; Quittell, L.M.; Marshall, B.C.; Mogayzel, P.J., Jr. Diagnostic Sweat Testing: The Cystic Fibrosis Foundation Guidelines. J. Pediatr. 2007, 151, 85-89. [CrossRef]

12. Morinville, V.D.; Husain, S.Z.; Bai, H.; Barth, B.; Alhosh, R.; Durie, P.R.; Freedman, S.D.; Himes, R.; Lowe, M.E.; Pohl, J.; et al. Definitions of Pediatric Pancreatitis and Survey of Present Clinical Practices. J. Pediatr. Gastroenterol. Nutr. 2012, 55, 261-265. [CrossRef]

13. Terlizzi, V.; Lucarelli, M.; Salvatore, D.; Angioni, A.; Bisogno, A.; Braggion, C.; Buzzetti, R.; Carnovale, V.; Casciaro, R.; Castaldo, G.; et al. Clinical expression of cystic fibrosis in a large cohort of Italian siblings. BMC Pulm. Med. 2018, 18, 196. [CrossRef]

14. Castaldo, A.; Iacotucci, P.; Carnovale, V.; Cimino, R.; Liguori, R.; Comegna, M.; Raia, V.; Corso, G.; Castaldo, G.; Gelzo, M. Salivary cytokines and airways disease severity in patients with cystic fibrosis. Diagnostics 2020, 10, 222. [CrossRef]

15. Bergougnoux, A.; D’Argenio, V.; Sollfrank, S.; Verneau, F.; Telese, A.; Postiglione, I.; Lackner, K.J.; Claustres, M.; Castaldo, G.; Rossmann, H.; et al. Multicenter validation study for the certification of a CFTR gene scanning method using next generation sequencing technology. Clin. Chem. Lab. Med. 2018, 56, 1046-1053. [CrossRef]

16. Tomaiuolo, R.; Sangiuolo, F.; Bombieri, C.; Bonizzato, A.; Cardillo, G.; Raia, V.; D’Apice, M.; Bettin, M.; Pignatti, P.; Castaldo, G.; et al. Epidemiology and a novel procedure for large scale analysis of cftr rearrangements in classic and atypical CF patients: A multicentric Italian study. J. Cyst. Fibros. 2008, 7, 347-351. [CrossRef]

17. Terlizzi, V.; Carnovale, V.; Piccialli, G.; Castellani, C.; Cirilli, N.; Colombo, C.; Corti, F.; Cresta, F.; D'Adda, A.; Lucarelli, M.; et al. Clinical expression of patients with the D1152H CFTR mutation. J. Cyst. Fibros. 2015, 14, 447-452. [CrossRef]

18. Terlizzi, V.; Piccialli, G.; Salvatore, D.; Lucarelli, M.; Raia, V.; Angioni, A.; Carnovale, V.; Cirilli, N.; Casciaro, R.; Colombo, C.; et al. Genotype-phenotype correlation and functional studies in patients with cystic fibrosis bearing CFTR complex alleles. J. Med Genet. 2017, 54, 224-235. [CrossRef]

19. Sofia, V.M.; Surace, C.; Terlizzi, V.; Da Sacco, L.; Alghisi, F.; Angiolillo, A.; Braggion, C.; Cirilli, N.; Colombo, C.; Di Lullo, A.; et al. Trans-heterozygosity for mutations enhances the risk of recurrent/chronic pancreatitis in patients with Cystic Fibrosis. Mol. Med. 2018, 24, 38. [CrossRef]

20. Terlizzi, V.; De Gregorio, F.; Sepe, A.; Amato, N.; Arduino, C.; Casale, A.; Majo, F.; Tomaiuolo, R.; Castaldo, G.; Raia, V. Brand new SPINK1 and CFTR mutations in a child with acute recurrent pancreatitis: A case report. Minerva Pediatr. 2013, 65, 669-672. [PubMed]

21. Terlizzi, V.; Mergni, G.; Centrone, C.; Festini, F.; Taccetti, G. Trend of sweat chloride values in a cohort of patients carrying CFTR mutations of varying clinical consequence: Is there a risk of increasing sweat chloride over time? Pediatr. Pulmonol. 2020, 55, 1089-1093. [CrossRef]

22. Terlizzi, V.; Mergni, G.; Buzzetti, R.; Centrone, C.; Zavataro, L.; Braggion, C. Cystic fibrosis screen positive inconclusive diagnosis (CFSPID): Experience in Tuscany, Italy. J. Cyst. Fibros. 2019, 18, 484-490. [CrossRef]

23. Salvatore, D.; Padoan, R.; Buzzetti, R.; Amato, A.; Giordani, B.; Ferrari, G.; Majo, F. Patients with cystic fibrosis having a residual function mutation: Data from the Italian registry. Pediatr. Pulmonol. 2019, 54, 150-157. [CrossRef] 
24. McKone, E.F.; Emerson, S.S.; Edwards, K.L.; Aitken, M.L. Effect of genotype on phenotype and mortality in cystic fibrosis: A retrospective cohort study. Lancet 2003, 361, 1671-1676. [CrossRef]

25. Salvatore, D.; Terlizzi, V.; Francalanci, M.; Taccetti, G.; Messore, B.; Biglia, C.; Pisi, G.; Calderazzo, M.A.; Caloiero, M.; Pizzamiglio, G.; et al. Ivacaftor improves lung disease in patients with advanced cf carrying CFTR mutations that confer residual function. Respir. Med. 2020, 171, 106073. [CrossRef]

Publisher's Note: MDPI stays neutral with regard to jurisdictional claims in published maps and institutional affiliations.

(C) 2020 by the authors. Licensee MDPI, Basel, Switzerland. This article is an open access article distributed under the terms and conditions of the Creative Commons Attribution (CC BY) license (http://creativecommons.org/licenses/by/4.0/). 